\title{
The BRIC-GARN Meeting 2011: of mice and men
}

\author{
David S Pisetsky*
}

Mice were very much on the minds of guests staying at the Hilton Tokyo Bay from 14 to 16 November 2011. The hotel is a short distance from Tokyo Disneyland and, for most guests, the mice were of the cartoon variety that descended from Steamboat Willie. Now known as Mickey Mouse, Steamboat Willie was the brilliant product of Walt Disney's imagination. Not surprisingly, more than a few children cavorting in the hotel lobby wore the iconic black ears as treasured souvenirs of their trip to the Magic Kingdom.

The other Hilton guests thinking about mice were attending the BRIC-GARN Meeting 2011. This outstanding international congress, organized by Professor Kusuki Nishioka, Director and Chairman, Institute of Medical Science, Tokyo, encompassed both the Bio-Rheumatology International Congress (BRIC) and the ninth Global Arthritis Research Network (GARN) meeting. The GARN meeting brings together investigators from around the world to discuss the pathogenesis and treatment of inflammatory arthritis. For these people, the mice uppermost in the mind were of the knockout and transgenic kind. Indeed, one of the highlights of the meeting was a presentation on slickly engineered rodents whose cells glowed neon-bright to track the peregrinations of an overexpressed fluorescent protein construct.

Among tissues featured at the meeting, bone received significant attention - especially with regard to the interface with the immune system. Indeed, bone - often viewed as an inert, albeit durable and hard, scaffold for the body construction - is intensively dynamic as osteoclasts and osteoblasts engage in relentless surface remodeling. In this lively cellular pas de deux, RANKRANKL interactions are at the center of action. As therapies targeting RANKL enter practice, questions will abound on the consequences of its inhibition, not only for the bone itself but for the immune cells that also utilize this system. Indeed, as described by Professor Yongwon Choi from University of Pennsylvania in his study on a molecule called OSCAR, osteoclasts and osteoclasts have many similarities to $\mathrm{T}$ cells and

*Correspondence: piset001@mc.duke.edu

Duke University Medical Center, 151G, Durham VAMC, Durham, NC 27705, USA antigen-presenting cells; bone cells are homebodies, however, whereas immune cells are wanderers.

Another cell in the spotlight at the meeting was the fibroblast. As shown in studies by Professor Steffen Gay from Zurich, synovial fibroblasts play a key role in the pathogenesis of rheumatoid arthritis (RA), with an invasive and destructive phenotype bearing the hallmark of epigenetic modification. The driving force of such modification is not known but the presence of aberrant base methylation suggests that pathogenesis involves changes to the DNA at the cellular level. As such, agents that undo epigenetic modification could have therapeutic benefit by reconfiguring genes and returning the fibroblasts to a more subdued and tractable state. Intriguingly, one compound that has potential as an epigenetic modifier is $S$-adenosyl methionine. Called SAME (pronounced Sammy), this agent has long had popularity as an alternative therapy for RA and was touted on American television by the actor James Coburn of Our Man Flint fame. Coburn himself had severe RA. Imagine the irony if SAME turned out to be the real deal.

Professor Gay also highlighted the importance of miRNA in the regulation of fibroblast biology. miRNA is hot right now and the role of these regulatory nucleic acids was reprised in presentations by Professor Iain McInnnes from Glasgow and Professor Nan Shen from Shanghai. Many studies in the future will no doubt investigate miRNA signatures as biomarkers comparable with mRNA signatures. The potential of miRNAs as targets of therapy remains to be tested, however, with such approaches possibly encountering the same obstacles as did antisense; the delivery of nucleic acids inside cells can be a challenge to say the least. Thus far, synovial fibroblasts have not been put directly in the cross-hairs of a targeted therapy, although undoubtedly many current agents can affect the function of these cells by reducing the activity of other interacting cell types and their production of mediators.

A study by Professor Ulf Muller-Ladner from Giessen raised the intriguing possibility that synovial fibroblasts can migrate from joint to joint, in essence causing synovitis to metastasize. These experiments were performed in a SCID mouse model in which synovial tissue and cartilage from a patient are implanted into the mouse and cell migration is tracked by 
immunofluorescence. Interestingly, in this model, cartilage damage may be necessary to provide a stopping place for fibroblasts on the lookout for a new place to wreak havoc. Thus, while the implanted human cartilage suffered the attack of the fibroblasts, the joints of the mouse remain unperturbed. Such observations could suggest that, while RA has a strong component of autoimmunity, tissue injury may be critical to initiate the process.

As studies of new models show, mice can provide exceptionally powerful systems for detailed molecular dissection and can suggest novel mechanisms by which synovial inflammation can arise. While mouse models will remain a mainstay of investigation in rheumatology, there is nevertheless uncertainty about their value to predict treatment responses in man. The road for any new product to the clinic will inevitably pass through the cages of inbred mice, but demonstration of the efficacy of a new therapy for RA or systemic lupus erythematosus in mice is no guarantee of success in man. As described by Professor Peter Lipsky (Charlottesville), the success of Bcell-directed therapy in mouse models of lupus has yet to be replicated in man. While trial design issues may hamper drug testing in patients, human and murine lupus may be sufficiently different to preclude a smooth and easy translation. Given the current costs of developing a new agent, such uncertainty can be chilling to companies, investigators and investors.

Together, studies of both murine and human disease have produced an abundance of data to construct models for pathogenesis. These models can be represented schematically as branched networks like a circuit diagram, although they grow ever more complex with multiple arrows connecting cell types, on the one hand, and signaling pathways, on the other. Such schematic representations, while informative, are inherently limited because of their two-dimensional nature. At least four dimensions, including time, will be required for modeling a complex disease like arthritis. Furthermore, in disease pathogenesis there are many unknown unknowns including mediators driving synovitis that are yet to be identified. Thus, as described by Professor McInnes, synovial fluid contains a component that can drive synovial fibroblasts. While this component has potent activity, its identity is a mystery. In addition to difficulties with unknown players, the schematic representations do not put value signs on the interactions. No doubt some arrows are thin and some are thick, but we do not know which is which.

The role of the nervous system must also be considered in understanding the pathogenesis of RA as well as the response to treatment. RA is an inherently painful condition and, as shown elegantly by Professor Georg Schett from Erlangen, TNF can be a powerful mediator of pain. Indeed, some of the dramatic and almost immediate treatment responses of TNF blockers may result from their profound analgesic effects and the modulation of central pain pathways. Such effects may not occur with other biological or targeted therapies that, while effective, may not produce the same clash of the therapeutic cymbal that excites hopes of a revolutionary advance. Professor Nishioka also discussed pain from the perspective of fibromyalgia and the development of new measures to characterize this important condition, which can occur alone or as a consequence of diseases such as RA and systemic lupus erythematosus.

In this setting, the presentation of the Masterswitch initiative by Professor Tom Huizinga of Lieden provided the basis for lively discussion. Masterswitch is a program of the European Union that involves sites around the continent to identify key points in the pathogenesis of inflammatory arthritis that are putatively switched on during disease and, hopefully, can be switched off during therapy. Professor Huizinga described the expression of IgE antibodies to citrullinated proteins as one such possible switch event. While the role of the basophil in RA pathogenesis has long been suspected, the presence of IgE antibodies to citrullinated proteins provides a neat way to trigger these cells to dump their contents into the witch's brew that boils in the rheumatoid joint.

How many switches will there be and will any have mastery over the others? My take on the literature is that RA is a process that can be switched on and switched off in many different ways. Indeed, consideration of the properties of existing disease-modifying anti-rheumatic drugs fails to reveal any common or unifying action, beyond restraining overall immune activity. In this case, a rheostat may be a better analogy than a switch. Fortunately, current therapy can produce impressive results, with evidence that at least some patients treated with biological agents can have therapy withdrawn and still show disease control. Perhaps a withdrawal phase should be part of clinical trials in the future. For reasons of costs and safety, we need to know whether continued treatment with biological agents is necessary once remission is obtained and to develop ways to identify when disease is truly quiescent.

For those not old enough to remember the excitement, awe and even frenzy that the idea of Disneyland engendered, the original television program and park featured four different lands - Fantasyland, Frontierland, Tomorrowland, and Adventureland. In the same way, a good science meeting like BRIC-GARN inhabits different lands and the terminology would not be too different since scientists like to think about the future, have adventures, and forge new frontiers. Fantasy can also be a healthy part of science. While I do not think there was too much fantasy at the Tokyo meeting, many people 
nevertheless thought treating RA with a monoclonal anti-cytokine antibody, as described by Professor Tiny Maini from London, was worthy of a place just next to the Mad Tea Party and Pinocchio's Daring Journey. Like the others who were fortunate to attend this meeting, I had a wonderful time near the Magic Kingdom and await with great interest the opportunity to explore the new lands of arthritis research and therapy.

\section{Abbreviations}

BRIC, Bio-Rheumatology International Congress; GARN, Global Arthritis Research Network; miRNA, microRNA; RA, rheumatoid arthritis; RANK, receptor activator of nuclear factor-KB; RANKL, receptor activator of nuclear factor-KB ligand; TNF, tumor necrosis factor.

Published: 24 February 2012

\section{References}

1. Barrow AD, Raynal N, Andersen TL, Slatter DA, Bihan D, Pugh N, Cella M, Kim T, Rho J, Negishi-Koga T, Delaisse JM, Takayanagi H, Lorenzo J, Colonna M, Farndale RW, Choi Y, Trowsdale J: OSCAR is a collagen receptor that costimulates osteoclastogenesis in DAP12-deficient humans and mice. J Clin Invest 2011, 121:3505-3516.

2. Choi Y, Walsh MC, Arron JR: Between bedside and bench: breaking into bone biology - target practice. Nat Med 2009, 15:144-145.

3. Dörner T, Giesecke C, Lipsky PE: Mechanisms of B cell autoimmunity in SLE. Arthritis Res Ther 2011, 13:243.

4. Hess A, Axmann R, Rech J, Finzel S, Heindl C, Kreitz S, Sergeeva M, Saake M, Garcia M, Kollias G, Straub RH, Sporns O, Doerfler A, Brune K, Schett G: Blockade of TNF-a rapidly inhibits pain responses in the central nervous system. Proc Natl Acad Sci U S A 2011, 108:3731-3736.

5. Hirano T: Interleukin 6 in autoimmune and inflammatory diseases: a personal memoir. Proc Jpn Acad Ser B Phys Biol Sci 2010, 86:717-730.
6. Karouzakis E, Gay RE, Gay S, Neidhart M: Epigenetic deregulation in rheumatoid arthritis. Adv Exp Med Biol 2011, 711:137-149.

7. Kurowska-Stolarska M, Alivernini S, Ballantine LE, Asquith DL, Millar NL, Gilchrist DS, Reilly J, lerna M, Fraser AR, Stolarski B, McSharry C, Hueber AJ, Baxter D, Hunter J, Gay S, Liew FY, McInnes IB: MicroRNA-155 as a proinflammatory regulator in clinical and experimental arthritis. Proc Nat/ Acad Sci U S A 2011, 108:11193-11198.

8. Nakamura I, Takahashi N, Jimi E, Udagawa N, Suda T: Regulation of osteoclast function. Mod Rheumatol 2011. [Epub ahead of print]

9. Nakashima T, Hayasi M, Fukunaga T, Oh-Hora M, Feng JQ, Bonewald LF, Kodama T, Wutz A, Wagner EF, Penninger JM, Takayanagi H: Evidence of osteocyte regulation of bone homeostasis through RANKL expression. Nat Med 2011, 17:1231-1234.

10. Neumann E, Lefèvre S, Zimmermann B, Gever M, Lehr A, Umscheid T, Schönburg M, Rehart S, Müller-Ladner U: Migratory potential of rheumatoid arthritis synovial fibroblasts: additional perspectives. Cell Cycle 2010, 9:2286-2291.

11. Schuerwegh AJ, loan-Facsinay A, Dorjée AL, Roos J, Bajema IM, van der Voort El, Huizinga TW, Toes RE: Evidence for a functional role of lgE anticitrullinated protein antibodies in rheumatoid arthritis. Proc Natl Acad SciU SA 2010, 107:2586-2591.

12. Tang Y, Luo X, Cui H, Ni X, Yuan M, Guo Y, Huang X, Zhou H, de Vries N, Tak PP, Chen S, Shen N: MicroRNA-146a contributes to abnormal activation of the type I interferon pathway in human lupus by targeting the key signaling proteins. Arthritis Rheum 2009, 60:1065-1075.

13. Usui C, Hatta K, Aratani S, Yagishita N, Nishioka K, Kanazawa T, Ito K, Yamano Y, Nakamura H, Nakajima T, Nishioka K: The Japanese version of the 2010 American College of Rheumatology preliminary diagnostic criteria for fibromyalgia and the fibromyalgia symptom scale: reliability and validity. Mod Rheumatol 2011. [Epub ahead of print]

doi:10.1186/ar3698

Cite this article as: Pisetsky DS: The BRIC-GARN Meeting 2011: of mice and men. Arthritis Research \& Therapy 2012, 14:107. 